\title{
Rival behavior and the elicitation of aggression at the boundary and inside the territory of a convict cichlid: A methodological note
}

\author{
HARMAN V. S. PEEKE and SHIRLEY C. PEEKE \\ University of California, San Francisco, California 94143
}

\begin{abstract}
Aggression emitted by territorial convict cichlids was studied both in response to a nonterritorial conspecific confined in a glass tube intruded into a territory and to an adjacent territorial conspecific protected by a clear partition. It was demonstrated that there is a high positive correlation between the number of threat displays emitted by the two antagonists during border disputes. The number of threat displays given by an intruder, on the other hand, has a low correlation with the number of threat displays of the territorial resident. Requirements for recording data from the stimulus fish is thus dependent on the method used.
\end{abstract}

Laboratory studies of aggression in fish frequently use one of two procedures for studying aggressive interactions. In one procedure, the aggressive interaction is between two resident fish in adjacent territories. In the other, the interaction is between a territorial resident and a nonterritorial intruder. In the case of the rival intruded into the territory of the resident fish, we have a laboratory analog of a wandering fish that intrudes into a territory. In the other situation, we have a laboratory analog of fighting at the common boundary during the early stages of territorial establishment.

This study investigates the interaction of the behavior of one antagonist on the behavior of the other by correlating the behavior of a territorial resident and the behavior of an antagonist in the two situations described above. In one experiment, the resident was confronted with a same-sex conspecific intruded into his territory. In a second experiment, two same-sex conspecific residents were inhabiting adjoining territories, but until the experiment started, they had not seen each other. The dependent variable was the frequency of threat displays emitted by the two antagonists. The question asked was the following: What is the overall relationship between the number of threat displays emitted by the two antagonists in each procedure? The study was designed so that factors such as size of antagonist and distance from the territory center were held constant. These factors have been demonstrated to have important effects in modulating the amount of aggression emitted by the species used in this study, the convict cichlid (Peeke, Avis, \& Peeke, Note 1).

As reported in the literature, the typical procedure used in both types of studies is to prevent the two fish

This research was supported in part by BRS Grant RR05755-02 to the Langley Porter Institute, University of California, San Francisco. Requests for reprints should be sent to H. V. S. Peeke, Brain-Behavior Research Center, University of California, Sonoma State Hospital, Eldridge, California 95431. from making physical contact with each other by a glass partition separating them. In many studies with several species of fish, the intruder is enclosed in a clear glass tube and placed inside the boundaries of the resident's territory. Aggression (and other kinds of behavior as well) is assessed by recording the resident's behavior toward the intruder. This method has been used in many of the classic studies of stickleback behavior (e.g., Sevenster, 1961; Sevenster-Bol, 1962; van Iersel, 1953). More recently, the method has been used in studies specifically concerned with the aggressive and territorial behavior of sticklebacks (Peeke, 1969; Peeke \& Veno, 1973, 1975; van den Assem \& van den Molen, 1969) and other species as well (e.g., Avis \& Peeke, 1975; Peeke, Avis, \& Ellman, 1975, with convict cichlid; Peeke \& Peeke, 1970, with Siamese fighting fish).

Reviewers of papers using this method have frequently criticized the method because the behavior of the stimulus fish is rarely reported and the reader must be content with unpublished assurances from the investigator that the behavior of the confined stimulus fish does not have a pronounced effect on the behavior of the territorial resident. The procedure of using clear partitions to artificially separate adjacently territorial fish has also received criticism for the same reasons. The criticism has been somewhat blunted by two reports that discuss the interrelationship of the behavior of one fish on that of the other (Peeke, Herz, \& Gallagher, 1971, with convict cichlids; van den Assem \& van den Molen, 1969, with sticklebacks).

\section{METHOD}

In Experiment 1, 35 adult male convict cichlids were placed individually into aquariums $(60 \times 30 \times 30 \mathrm{~cm})$ and allowed 5 days to acclimatize to their surroundings. The floor was covered with coarse gravel and a ceramic flower pot, lying on its side, was placed $10 \mathrm{~cm}$ from one end of the tank. The pot served as a refuge and may be considered the center of the territory. 
Air-driven filters provided circulation and filtration. Water temperature was maintained at $25^{\circ} \mathrm{C}\left( \pm 2^{\circ} \mathrm{C}\right)$. Fish were fed live brine shrimp and dried flake food daily. Light was maintained on a $14 \mathrm{~h}$ on, $10 \mathrm{~h}$ off cycle. An equal number of adult male convict cichlids were housed in a similar manner but were transferred to a clear glass tube $10 \mathrm{~cm}$ in diameter and placed in the resident's tank, $25 \mathrm{~cm}$ from the entrance to the pot. One experimenter recorded the behavior of the intruder, the other the behavior of the resident. Recording was accomplished by depressing a button on a hand-held console, and the data were registered on an impulse counter. Behavior recorded was the threat display (gill-cover extension and erection of the dorsal and ventral fins). Observation and recording began as soon as the resident approached to within $10 \mathrm{~cm}$ of the intruder. Recording was continued for $8 \mathrm{~min}$.

In Experiment 2, 74 fish from the same stock were introduced, 2 to a tank, into halves of aquariums $(100 \times 30 \times 30 \mathrm{~cm})$ divided in the center by a clear glass partition that was parallel to an opaque partition. Again, 5 days were allowed for acclimatization. Each compartment had a floor covered with coarse gravel and a ceramic flower pot, lying on its side, $10 \mathrm{~cm}$ from the end of the tank. The flower pots faced the transparent/opaque screen. Temperature and light cycle were the same as in Experiment 1 , and the fish were fed the same food. One experimenter observed the fish on the right side, another the fish on the left. The experiment commenced when the opaque partition was removed. Observation and recording were begun as soon as both of the subject fish were within $10 \mathrm{~cm}$ of the clear glass partition. Recording was continued for a total of $8 \mathrm{~min}$.

\section{RESULTS}

In Experiment 1, the correlation (Pearson $\mathrm{r}$ ) between the resident and the intruder for frequency of threat displays was +.36 . The mean display frequency for the resident was 82.0 , and for the intruder, 51.3. This correlation is reliably greater than zero $(p<.05)$, but the coefficient of determination $\left(\mathrm{r}^{2}=.13\right)$ indicates that the proportion of variance accounted for by the correlation is very small. Hence, it would appear that the frequency of threat behavior of the resident fish is determined in large measure by factors other than the threat behavior of the intruding fish.

In Experiment 2, the correlation between the adjacently territorial fish was +.79 . The mean display frequency for the right-side fish was 40.7 , and for the left-side fish, 50.4. This correlation is also reliably greater than zero $(p<.01)$. In addition, the coefficient of determination $\left(r^{2}=.63\right)$ indicates that there is much common variance between the threat behavior of the two fish, suggesting that the threat behavior of one fish has much in common with the other.

While both correlations are statistically significant, there is a significant difference between the two $(\mathrm{z}=$ $2.818, \mathrm{p}<.003)$. Thus we can place confidence in the different proportion of the variance accounted for by the correlation in the two situations.

\section{DISCUSSION}

These results demonstrate that the threat behavior of an intruding conspecific has little to do with the amount of aggres- sion shown by the territorial resident in this laboratory analog of a situation where a territorial cichlid is confronted by a conspecific that has entered his territory, whereas the behavior of two adjacently territorial fish separated by a clear glass partition share considerable common variance, indicating that the behavior of one fish in the pair is dependent on the behavior of the other antagonist, or, alternatively, that they are modulated by some common factor. It is also clear that there is a very reliable difference between these kinds of observations and that generalizations from one paradigm to the other must be made with caution.

Alternatively, these results are what would be expected, insofar as, in nature, a wandering intruder is almost always attacked, his behavior having seemingly little to do with the probability of initial attack. Thus the correlation between the behavior of the stimulus fish in the clear glass tube and the territorial resident would be expected to be low. On the other hand, a dispute at the boundary of two territories would be more likely to be even, each fish being unlikely to flee or to enter the defended territory, and the correlation would be expected to be high.

The difference between the conditions might be accounted for by the greater freedom of the territorial boundary antagonist to move about, compared with the confinement of the intruded stimulus fish. However, we have used the tube-confined fish in studies where the intruder is presented at the periphery of the territory. In that situation, the behavior of the stimulus fish correlated highly with that of the territorial resident (Peeke \& Peeke, Note 2).

The results reported here are corroborated by data from independent experiments using different species in one or the other of these paradigms. Peeke and Peeke (1970), using intruded conspecifics in glass tubes in a study with Siamese fighting fish, observed no significant correlation between the behavior of the intruder and that of the resident. However, Meliska and Meliska (Note 3 ) found correlations as high as +.80 between the aggression of two Siamese fighting fish on either side of a clear partition separating their "territories."

The methodological implications of these findings are that, at least with this species, the investigator can use the "intruder confined in a clear glass tube" with little fear that the behavior of the intruder will be the major source of variance in his experiment. On the other hand, the results of the second experiment make it clear that investigators using adjacently territorial fish should monitor and report the behavior of both antagonists.

\section{REFERENCE NOTES}

1. Peeke, H. V. S., Avis, H. H., \& Peeke, S. C. Motivational variables and the sensitization and habituation of aggression in the convict cichlid (Cichlasoma nigrofasciatum). Manuscript submitted for publication, 1979.

2. Peeke, H. V. S., \& Peeke, S. C. Parental behavior and the sensitization and habituation of aggression in the convict cichlid. Manuscript in preparation, 1979.

3. Meliska, J. A., \& Meliska, C. J. Mirror-elicited threat display and combat aggression in Betta splendens. Paper presented at the meetings of the Animal Behavior Society, Seattle, Washington, 1978.

\section{REFERENCES}

Avis, H. H., \& Peeke, H. V. S. Differentiation by morphine of two types of aggressive behavior in the convict cichlid (Cichlasoma nigrofaciatum). Psychopharmacologia, 1975, 43, 287-289.

Peeke, H. V. S. Habituation of conspecific aggression in the three-spined stickleback (Gasterosteus aculeatus). Behavior, 1969, 35, 137-156. 
Peeke, H. V. S., Herz, M. J., \& Gallagher, J. E. Changes in aggressive interaction in adjacently territorial convict cichlids (Cichlasoma nigrofaciatum). Behaviour, 1971, 40, 43-54.

Pezke, H. V. S., \& Peeke, S. C. Habituation of aggressive responses in the Siamese fighting fish (Betta splendens). Behaviour, 1970, 36, 232-245.

Peeke, H. V. S., Peeke, S. C., Avis, H. H., \& Ellman, G. L. Alcohol, habituation and the patterning of aggressive responses in a cichlid fish. Pharmacology, Biochemistry and Behavior, 1975, 3, 1031-1036.

Peeke, H. V. S., \& Veno, A. Stimulus specificity of habituated aggression in three-spined sticklebacks (Gasterosteus aculeatus). Behavioral Biology, 1973, 8, 427-431.

PeEke, H. V. S., \& Veno, A. Response independent habituation of territorial aggression in the three-spined stickleback (Gasterosteus aculeatus). Zeitschrift für Tierpsychologie, 1975, 40 , 53-58.
Sevenster, P. A causal analysis of a displacement activity (fanning) in Gasterosteus aculeatus. Behaviour Supplement, 1961, 9, 1-170.

Sevenster-Bol, A. C. A. On the causation of drive reduction after consummatory act (in Gasterosteus aculeatus). Archieves Neerland Zoologie, 1962, 15, 175-236.

Van Den Assem, J., \& Van Der Molen, J. Waning of the aggressive response in the three-spined stickleback upon constant exposure to a conspecific: I. A preliminary analysis of the phenomenon. Behaviour, 1969, 34, 286-324.

Van IE rSel, J. J. A. An analysis of the parental behavior of the male three-spined stickleback. Behaviour Supplement, 1953, 3, 1-231.

(Received for publication May 23, 1979.) 